\title{
Cross-sectional correlates of fasting hyperinsulinaemia in post-menopausal women of different ethnic origin
}

\author{
A. D. Pradhan*†, J. E. Manson*‡§, S. L. Hendrix I, K. C. Johnson**, L. E. Wagenknecht††,

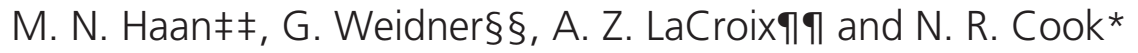

*Division of Preventive Medicine, †Division of Cardiology and $\neq$ Channing Laboratory, Department of Medicine, Brigham and Women's Hospital and Harvard Medical School, §Department of Epidemiology, Harvard School of Public Health, Boston, MA, ףDepartment of Obstetrics and Gynaecology, Hutzel Hospital, Wayne State University, Detroit, Ml, **Department of Preventive Medicine, University of Wisconsin Medical School, Madison, WI +†Department of Public Health Sciences, Wake Forest University School of Medicine, Winston-Salem, NC, $¥ \neq$ Department of Epidemiology, University of Michigan School of Public Health, Ann Arbor, Ml, §§Preventive Medicine Research Institute, Sausalito, CA and IाWWomen's Health Initiative Clinical Coordinating Center, Fred Hutchinson Cancer Research Center, Seattle, WA, USA

Accepted 6 June 2005

Final Acceptance 26 August 2005

\begin{abstract}
Aims In a large ethnically diverse nationwide sample of post-menopausal women we explored the relationship between fasting insulin levels, ethnicity, and a wide range of anthropometric, socio-economic, and lifestyle factors.
\end{abstract}

Methods Subjects were post-menopausal women aged 50-79 years without diagnosed diabetes mellitus comprising a subsample $(n=3500)$ of the Women's Health Initiative (WHI) Clinical Trial and Observational Study. In a crosssectional survey at baseline, we analysed the association between ethnicity and fasting insulin using analysis of covariance procedures and identified independent correlates of hyperinsulinaemia, defined by the 75 th percentile cut point for each ethnic group.

Results Fasting insulin levels were higher among African-American and Hispanic women than among non-Hispanic White or Asian women. These differences persisted after adjustment for age, educational attainment, total and central body obesity, adult weight change, family history of diabetes, smoking status, alcohol consumption, use of menopausal hormone therapy and physical activity. Higher levels of body mass index, waist-hip ratio, adult weight gain, and lower levels of total and moderate or strenuous recreational activity were independent correlates of fasting hyperinsulinaemia. Habitual walking was also inversely associated with fasting insulin.

Conclusions In this cross-sectional analysis, fasting insulin levels were higher among African-American and Hispanic post-menopausal women as compared with non-Hispanic White and Asian women. In addition, obesity, adult weight gain, and low levels of moderate or strenuous physical activity were independently associated with hyperinsulinaemia.

Diabet. Med. 23, 77-85 (2006)

Keywords hyperinsulinaemia, women, ethnicity

Abbreviations ACE, angiotensin-converting enzyme; BMI, body mass index; CHD, coronary heart disease; CT, clinical trial; DM, diabetes mellitus; HDL, high-density lipoprotein; LDL, low-density lipoprotein; MET, ratio of metabolic rate during the activity to the resting metabolic rate; MHT, menopausal hormone therapy; OS, observational study; WHI, Woman's Health Initiative; WHR, waisthip ratio
Correspondence to: Aruna D. Pradhan, Division of Preventive Medicine, Brigham and Women's Hospital, 900 Commonwealth Avenue, Boston, MA 02115, USA. E-mail: apradhan@partners.org

\section{Introduction}

Several prospective studies suggest that elevated fasting insulin is a predictor of Type 2 diabetes mellitus (DM) [1-7] and may predict coronary heart disease (CHD) [8-10] incidence in both normoglycaemic individuals and those with overt disorders of 
glucose tolerance. Fasting hyperinsulinaemia commonly coexists with other risk determinants for both conditions, including total and abdominal obesity and lifestyle factors such as physical inactivity, alcohol consumption, smoking, and dietary fat and carbohydrate intake. Elucidation of correlates of hyperinsulinaemia may be of particular importance among ethnic minority groups, especially African-Americans and Hispanics, who experience a two- to threefold excess diabetes prevalence [11-14] as compared with non-Hispanic White people. Moreover, age-standardized diabetes prevalence rates among minority women are $25-40 \%$ higher than corresponding rates among minority men [15]. Compounding this gender effect, previous studies have shown that menopause and ageing are both associated with diminished insulin sensitivity [16]. It has been hypothesized that loss of this 'insulin advantage' $[17,18]$ may account, in part, for the excess CHD risk observed among post-menopausal women. These intriguing observations underscore the need to identify potentially modifiable risk factors for hyperinsulinaemia, with the ultimate aim of developing strategies for primary prevention in these vulnerable populations.

Few studies have systematically evaluated determinants of fasting hyperinsulinaemia among ethnically diverse cohorts of post-menopausal women. The Women's Health Initiative Clinical Trials (CT) and Observational Study (OS) provide a unique setting in which to examine these issues. In a subsample of 3500 non-diabetic post-menopausal women in whom fasting insulin levels were available, we assessed ethnic difference in fasting insulin and explored potential correlates of fasting hyperinsulinaemia independent of a broad range of measured anthropometric, socio-economic, lifestyle and clinical risk factors.

\section{Patients and methods}

\section{Women's Health Initiative (WHI) study population}

The Women's Health Initiative has both CT and OS components, the objectives and design of which are described in detail elsewhere [19]. In brief, the WHI is a large clinical investigation of strategies for the prevention of several common causes of morbidity and mortality among post-menopausal women. Between 1993 and 1998, eligible post-menopausal women aged $50-79$ years were enrolled at one of 40 clinical centres nationwide. Enrollment of racial/ethnic minority groups in proportion to the US population of women 50-79 years of age (18.2\% according to the 1990 US census) was a priority.

Women were generally eligible for entry into the CT if they were post-menopausal, unlikely to change residence or die within 3 years, not known to have conditions that might affect adherence, and not currently participating in any other clinical trial. Of women screened, 68133 were enrolled in the four WHI CTs. Women who were found to be ineligible or unwilling for clinical trial enrolment were offered the opportunity to participate in the Observational Study. Recruitment directly into the OS also occurred; 93676 women enrolled in the OS.

\section{WHI CT-OS subsample selection}

Fasting blood specimens were collected from all women at baseline and, as part of the original protocol design, a subsample [approximately $8.6 \%$ of the menopausal hormone therapy (MHT) component, $4.3 \%$ of the DM component and $1 \%$ of OS participants] was selected for purposes of prospective assessment of WHI core blood analytes, including baseline fasting insulin. Using a pre-specified goal of sixfold oversampling for racial/ethnic minority women, subjects were randomly selected in the stated proportions from each of the WHI components. We excluded women with a history of diabetes and those having missing data for main covariates of clinical interest as predictors of hyperinsulinaemia. A positive history of diabetes was defined as self-reported treatment for diabetes with insulin and/ or oral hypoglycaemic agents and/or fasting plasma glucose $>7.0 \mathrm{mmol} / \mathrm{l}$. Based on these criteria, there were 4274 subjects available for analysis, 774 of whom were excluded because of missing values for the following variables: educational level $(n=31)$, body mass index (BMI) $(n=33)$, waist-hip ratio (WHR) $(n=20)$, weight change since age $18(n=50)$, family history of diabetes $(n=253)$, smoking status $(n=138)$, physical activity $(n=302)$, alcohol consumption $(n=41)$, and MHT use $(n=6)$, with some women missing data for more than one variable. The mean age (62.2 years), BMI $\left(28.7 \mathrm{~kg} / \mathrm{m}^{2}\right)$, and WHR $(0.81)$ for those women excluded were similar to those of the women included in the analysis (mean age $=62.6$ years, $\mathrm{BMI}=28.6 \mathrm{~kg} / \mathrm{m}^{2}$ and WHR $=0.82$ ). The final group included 3500 women. The study was reviewed and approved by Human Subjects Review Committees at each participating institution and signed informed consent was obtained from all women enrolled.

\section{Ascertainment and definition of clinical variables}

During initial screening visits personal information, including demographic characteristics, medical history, medication and vitamin supplement inventories, were reviewed. A personal habits questionnaire for assessment of smoking status, alcohol consumption and physical activity was completed and anthropometric measurements, blood pressure and fasting blood specimens were obtained. Fasting was defined as no food or beverage intake except water in the 12 -h period prior to blood collection.

Ethnicity was categorized as non-Hispanic White, AfricanAmerican, Hispanic, American Indian or Alaskan Native, Asian or Pacific Islander, or unknown (not one of the above) according to self-report. BMI was calculated as the weight in kilograms divided by the height in meters squared. The WHR was calculated as the ratio of the circumference of the waist at the natural waist or narrowest part of the torso and the maximal circumference of the hips measured to the nearest $0.1 \mathrm{~cm}$. A family history of diabetes was coded for individuals with a first-degree relative with diabetes mellitus. Adult weight change was classified according to answers to a question pertaining to change in weight during adult life since age 18 years. Possible responses were (i) weight has stayed about the same (within $10 \mathrm{lb}$ ), (ii) steady gain in weight, (iii) lost weight as an adult and kept it off, or (iv) weight has gone up and down again 
by more than $10 \mathrm{lb}$. Systolic and diastolic blood pressures were each measured after subjects had been seated and resting for $5 \mathrm{~min}$. Menopausal hormone therapy status was classified as never, past or current use of unopposed oestrogen and/ or oestrogen plus progestin from pills or patches.

Physical activity was quantified according to three separate variables defined as (i) total $\mathrm{kcal} / \mathrm{kg}$ per week expended from all recreational physical activity (including walking, mild, moderate and strenuous physical activity), (ii) minutes per week of moderate and strenuous recreational physical activity [including walking fairly fast defined as 3.5 miles $(5.6 \mathrm{~km})$ per hour or very fast defined as 4.5 miles $(7.2 \mathrm{~km})$ per hour, participating in activities such as jogging, aerobics, tennis, swimming, biking, use of an exercise machine, calisthenics, or popular or folk dancing], and (iii) energy expended per week from walking ( $\mathrm{kcal} / \mathrm{kg}$ per week) including fast walking among women reporting no other habitual strenuous physical activity. Those activities requiring an energy expenditure of 4.0-5.9 METs (ratio of metabolic rate during the activity to the resting metabolic rate) were defined as moderate intensity, 6.0 METs as strenuous [20]. For use in regression models, activity level was categorized into approximate quintiles for total energy expenditure from recreational physical activity and quartiles above zero for minutes per week of moderate or strenuous recreational physical activity and expenditure from walking, as there were a large proportion of women reporting no habitual participation in either of these latter activities.

\section{Ascertainment of dietary variables}

We assessed nutrient intake using a 122-item, semiquantitative food frequency questionnaire (FFQ) which ascertained average consumption of specific foods over the previous 3-month period. We excluded from analysis implausibly low or high scores for total intake of food or energy (less than 600 or more than $5000 \mathrm{kcal}$ per day). The reliability of the FFQ was previously assessed by correlation with 24-h dietary recalls and a 4-day food record [21]. In the current analysis, dietary data were available for 3328 (95.1\%) of women.

\section{Laboratory procedures}

Insulin was measured using a step-wise sandwich ELISA procedure on an ES 300 analyser (BMD-Roche Diagnostics, Indianapolis, IN, USA). This assay has $40 \%$ cross-reactivity with pro-insulin and $0 \%$ cross-reactivity with C-peptide. As part of a monthly quality assurance programme, the assay was monitored by the Diabetes Diagnostic Laboratory at the University of Missouri, Columbia. The coefficient of variation based on 173 blinded duplicates was $8.0 \%$.

\section{Statistical analysis}

Descriptive statistics were first calculated for the entire population. Differences in median fasting insulin levels between each ethnic subgroup and non-Hispanic white people were assessed using the Wilcoxon Rank Sum test. As fasting insulin was nonnormally distributed, geometric means and standard deviations were calculated for each ethnic group. Age-adjusted and multivariable-adjusted geometric means were determined using analysis of covariance of log insulin values with adjustment for age alone or with concurrent adjustment for potential confounders. Differences in geometric mean fasting insulin levels between non-Hispanic White people and other ethnic groups were tested by two-sample $t$-tests of least squares means of the log insulin values.

As we found significant differences in mean insulin levels according to ethnic group, we used ethnicity-specific cut points to defined elevated fasting insulin. As reference ranges for insulin differ according to the specific assay employed, no single universal cut point for hyperinsulinaemia has been established. Hyperinsulinaemia was therefore defined as a level in the upper fourth of the distribution for each ethnic group in accordance with the definition proposed by experts in the European Group for the Study of Insulin Resistance [22]. These cut-point values (pmol/l) were as follows for each ethnic group: 85.4 for nonHispanic White people, 108.7 for African-Americans, 108.3 for Hispanic Americans, 95.1 for American Indian/Alaskan Natives, 84.0 for Asian/Pacific Islanders, and 77.1 for women whose ethnicity was unknown or none of the above. In secondary analyses, we used ethnicity-specific 90th percentile cut points as an alternate definition of hyperinsulinaemia and also repeated the analysis using the total population 75 th percentile (93.1 pmol/1) with inclusion of ethnicity as a covariate in multivariable models. Odds ratios according to putative diabetes risk factors were estimated from logistic regression models with elevated fasting insulin as the dependent variable.

We assessed for interactions between ethnicity and risk factors among the three largest ethnic groups (non-Hispanic White people, African-Americans and Hispanics). In these analyses, potential risk factors were dichotomized according to socio-economic or clinically relevant cut points (age $>65$ years, education < high school, BMI $>25 \mathrm{~kg} / \mathrm{m}^{2}$, WHR $>0.8$, steady weight gain or fluctuation $>10$ pounds, positive family history of diabetes, current smoking, consumption of less than one alcoholic beverage per week, $<150$ min per week of moderate or strenuous physical activity and non-current MHT use).

\section{Results}

Descriptive statistics including the ethnic distribution of the study population are presented in Table 1. As shown, median fasting insulin levels among African-American and Hispanic women were significantly higher than the median for non-Hispanic white women. Age-adjusted and multivariableadjusted geometric mean insulin levels by ethnicity are presented in Table 2. In age-adjusted models, African-Americans and Hispanics had significantly higher mean insulin levels than non-Hispanic White women. Although Native Americans also appeared to have slightly higher mean fasting insulin levels, this difference did not achieve statistical significance. Fasting insulin levels among Asians were similar to non-Hispanic White women. Additional adjustment for a number of potential confounders and the presence of impaired fasting glucose attenuated the differences between mean fasting insulin levels, however, African-Americans and Hispanics had persistently higher levels compared with non-Hispanic White women. 
Table 1 Summary of clinical and biochemical parameters among the study population $(n=3500)$

\begin{tabular}{|c|c|}
\hline Characteristic & $\begin{array}{l}\text { Mean (SD), median } \\
\text { (IQR) or } n(\%)\end{array}$ \\
\hline Age (years), mean (SD) & $62.6(7.1)$ \\
\hline \multicolumn{2}{|l|}{ Ethnicity, $n(\%)$} \\
\hline Non-Hispanic White & $1910(54.6)$ \\
\hline African-American & $728(20.8)$ \\
\hline Hispanic & $435(12.4)$ \\
\hline American Indian/Alaskan Native & $70(2.0)$ \\
\hline Asian/Pacific Islander & $295(8.4)$ \\
\hline Unknown/none of the above & $62(1.8)$ \\
\hline \multicolumn{2}{|l|}{ Education, $n(\%)$} \\
\hline College degree or higher & $1252(35.8)$ \\
\hline School after high school & $1363(38.9)$ \\
\hline High school diploma or GED & $629(18.0)$ \\
\hline Less than high school & $256(7.3)$ \\
\hline Body mass index, $\mathrm{kg} / \mathrm{m}^{2}$, mean (SD) & $28.6(6.0)$ \\
\hline Waist-hip ratio, mean (SD) & $0.82(0.08)$ \\
\hline Systolic blood pressure $(\mathrm{mmHg})$ mean $(\mathrm{SD})$ & $127.9(17.6)$ \\
\hline Diastolic blood pressure (mmHg), mean (SD) & $76.1(9.2)$ \\
\hline Family history of diabetes, $n(\%)$ & $1292(36.9)$ \\
\hline \multicolumn{2}{|l|}{ Smoking status, $n(\%)$} \\
\hline Never smoked & $1943(55.5)$ \\
\hline Past smoker & $1296(37.0)$ \\
\hline Current smoker & $261(7.5)$ \\
\hline \multicolumn{2}{|l|}{ Alcohol intake, $n(\%)$} \\
\hline Non-drinker & $474(13.5)$ \\
\hline Past drinker & $661(18.9)$ \\
\hline$<1$ drink per month & $490(14.0)$ \\
\hline$<1$ drink per week & $781(22.3)$ \\
\hline 1-6 drinks per week & $794(22.7)$ \\
\hline$>7$ drinks per week & $300(8.6)$ \\
\hline \multicolumn{2}{|l|}{ MHT usage status, $n(\%)$} \\
\hline Never used & $1830(52.3)$ \\
\hline Past user & $652(18.6)$ \\
\hline Current user & $1018(29.1)$ \\
\hline $\begin{array}{l}\text { Energy expended from all recreational physical } \\
\text { activity (kcal/kg/week), median (IQR) }\end{array}$ & $7.0(1.5,15.5)$ \\
\hline $\begin{array}{l}\text { Minutes per week of moderate/strenuous } \\
\text { physical activity, median (IQR) }\end{array}$ & $20.0(0.0,125.0)$ \\
\hline $\begin{array}{l}\text { Energy expended from walking, median (IQR) } \\
\text { All participants }\end{array}$ & $1.9(0.0,6.3)$ \\
\hline $\begin{array}{l}\text { Those not engaging in strenuous physical } \\
\text { activity }(n=2718)\end{array}$ & $1.5(0.0,5.0)$ \\
\hline Current use of ACE-inhibitors, $n(\%)$ & $224(6.4)$ \\
\hline Current use of beta-blockers, $n(\%)$ & $238(6.8)$ \\
\hline Current use of diuretics, $n(\%)$ & $460(13.1)$ \\
\hline Current use of statins, $n(\%)$ & $224(6.4)$ \\
\hline Total cholesterol (mmol/l), mean (sD) & $5.75(0.97)$ \\
\hline LDL cholesterol (mmol/l), mean (SD) & $3.46(0.91)$ \\
\hline HDL cholesterol (mmol/l) mean (SD) & $1.55(0.40)$ \\
\hline Triglycerides (mmol/l) mean (SD) & $3.76(1.9)$ \\
\hline $\begin{array}{l}\text { Total cholesterol to HDL cholesterol ratio, } \\
\text { mean (SD) }\end{array}$ & $4.0(1.2)$ \\
\hline Fasting glucose (mmol/l) mean (SD) & $5.2(0.6)$ \\
\hline \multicolumn{2}{|l|}{ Fasting insulin $(\mathrm{pmol} / \mathrm{l})$, median (IQR) } \\
\hline Non-Hispanic White & $61.1(44.4,85.4)$ \\
\hline African-American & $77.1(56.3,108.7) * \dagger$ \\
\hline Hispanic & $72.9(51.4,108.3) * \dagger$ \\
\hline
\end{tabular}

Table 1 Continued

\begin{tabular}{lc}
\hline Characteristic & $\begin{array}{l}\text { Mean (SD), median } \\
(\mathrm{IQR}) \text { or } n(\%)\end{array}$ \\
Asian/Pacific Islander & $59.7(43.1,84.0)$ \\
Unknown/none of the above & $55.9(43.8,77.1)$ \\
\hline
\end{tabular}

GED, General Equivalency Diploma.

Means and standard deviations (SD) are presented for normally distributed variables, medians and interquartile ranges (IQR) are presented where indicated. Number of women $(n)$ and percentages (\%) are presented for proportions.

Differences in median fasting insulin levels between non-Hispanic White women and other ethnic groups were tested using the Wilcoxon Rank Sum test. ${ }^{*} P<0.001$.

Differences in median fasting insulin levels compared with the population median were tested using the Signed Rank test. $\dagger P<0.001$.

As insulin levels were higher among both African-American and Hispanic women, we used ethnicity-specific cut points in our analysis of risk factors for hyperinsulinaemia rather than a single population-based value. Hyperinsulinaemia was defined as a level above the highest quartile cut point in each ethnic group (Table 1). We found no statistically significant ethnicity by risk factor interactions and therefore did not stratify estimates of main effects according to ethnic background. In age-adjusted analyses, lower educational level, higher BMI and WHR, adult weight gain, a family history of diabetes, less frequent alcohol consumption, non-current MHT use, and all three physical inactivity measures were associated with a greater risk for fasting hyperinsulinaemia (Table 3). Current smoking was also associated with reduced odds of hyperinsulinaemia. These relationships were attenuated in multivariable analyses, but remained significant for indices of obesity, adult weight gain, current smoking and physical inactivity. We observed a progressive reduction in odds for hyperinsulinaemia according to increasing energy expended from all recreational physical activity with women in the highest vs. lowest category having a $47 \%$ decrease in odds $(95 \%$ CI 29 to $60 \%$; $P$-trend $<0.001)$. Participation in greater than $45 \mathrm{~min}$ per week of moderate or strenuous recreational physical activity was associated with significant declines in relative odds across categories. A similar inverse gradient was observed for women who engaged in walking among those reporting no other regular strenuous physical activity $(n=2718,77.7 \%$ of the study population).

We also assessed waist circumference as opposed to WHR as an alternate measure of abdominal adiposity. In these analyses, the age-adjusted and multivariable ORs according to increasing quartile of waist circumference were 1.0, 2.2, 3.9 and $10.9(P$-trend $<0.001)$ and 1.0, 1.6, 2.2 and $4.1(P$-trend $<0.001$ ), respectively, for quartiles defined as $<78.0$, $78.0-86.9,87.0-95.5$ and $>95.5 \mathrm{~cm}$. In secondary analyses evaluating the influence of an alternate cut point for the definition of hypersinsulinaemia, we found consistent results using ethnicity-specific 90th percentile thresholds. In brief, all 
Table 2 Age-adjusted and multivariable-adjusted geometric mean fasting insulin levels (pmol/l) by ethnicity

\begin{tabular}{llllll}
\hline & $\begin{array}{l}\text { Non-Hispanic } \\
\text { White }(n=1910)\end{array}$ & $\begin{array}{l}\text { African-American } \\
(n=728)\end{array}$ & $\begin{array}{l}\text { Hispanic } \\
(n=435)\end{array}$ & $\begin{array}{l}\text { American Indian/ } \\
\text { Alaskan Native }(n=70)\end{array}$ & $\begin{array}{l}\text { Asian/Pacific } \\
\text { Islander }(n=295)\end{array}$ \\
\hline Model 1 & $63.0(0.7)$ & $78.2(1.4)^{*}$ & $74.7(1.7)^{*}$ & $69.9(4.0)$ & $\begin{array}{l}\text { Unknown/none of the } \\
\text { other groups }(n=62)\end{array}$ \\
Model 2 & $65.2(0.6)$ & $70.6(1.1)^{*}$ & $71.4(1.5)^{*}$ & $68.5(3.4)$ & $60.0(1.7)$ \\
Model 3 & $65.4(0.6)$ & $70.3(1.1)^{*}$ & $71.7(1.5)^{*}$ & $68.0(3.3)$ & $66.1(1.7)$ \\
\hline
\end{tabular}

Model 1: age-adjusted in 5 year categories.

Model 2: adjusted for age (5-year categories), education (college degree or greater, school after high school, high school diploma or GED, less than high school), BMI (linear continuous), WHR (linear continuous), weight change (weight gain less than $10 \mathrm{lb}$, lost weight and maintained, steady gain, or weight fluctuation greater than $10 \mathrm{lb}$ ), family history of DM (no/yes), smoking (never, past or current), alcohol consumption (non-drinker, past drinker, $<1 \mathrm{drink} / \mathrm{month},<1 \mathrm{drink} /$ week, 1-6 drinks/week or 7+drinks/week), total energy expenditure (linear continuous), and MHT use (never/past/current). Model 3: model 2 additionally adjusted for elevated fasting glucose $(6.1-6.9 \mathrm{mmol} / 1$-yes $/ \mathrm{no})$.

Differences in geometric mean fasting insulin levels between non-Hispanic white women and other ethnic groups were tested by ANCova on the log-transformed levels. ${ }^{*} P<0.001$.

findings were similar with BMI, WHR, adult weight gain, smoking status and physical activity remaining the only significant factors after multivariable adjustment. In particular, the multivariable ORs according to increasing quartile of BMI and WHR were 1.0, 0.9, 1.9 and $5.2(P$-trend $<0.001)$ and $1.0,1.3,2.3$ and $4.2(P$-trend $<0.001)$. Our results were also similar when hyperinsulinaemia was defined by a value in the upper fourth of the overall population distribution of fasting insulin (93.1 pmol/l) with ethnicity included as a covariate in regression models. Using this latter approach, BMI, WHR, adult weight gain, smoking status and exercise measures remained the only significant factors in multivariable analysis.

Adjustment for dietary variables, including total energy consumption, total dietary fibre, total per cent fat and per cent carbohydrates among women with available dietary data ( $n=3328,95.1 \%$ of the study population) did not materially alter these results (data not shown). Our findings were also robust to adjustment for lipid levels [total cholesterol to highdensity lipoprotein (HDL) ratio and triglycerides level], blood pressure, use of diuretics, angiotensin-converting enzyme (ACE) inhibitors, beta-blockers or statins, and in models adjusting for impaired glucose tolerance defined as a fasting glucose level of $6.1-6.9 \mathrm{mmol} / \mathrm{l}$. In these statistical models, obesity, adult weight gain, smoking status and physical activity remained independent correlates of fasting hyperinsulinaemia.

\section{Discussion}

In this large cross-sectional study conducted among an ethnically diverse nationwide sample of post-menopausal women we found that, as in previous studies of younger men and women [23-25], fasting insulin levels are significantly higher among African-Americans and Hispanics than among nonHispanic White women. These results were independent of other major correlates of hyperinsulinaemia. We also identified BMI, WHR, adult weight gain, never smoking as opposed to current smoking, and total and moderate or strenu- ous recreational physical activity as strong independent correlates of elevated fasting insulin. These results agree with previous findings from smaller studies involving older women [26-29], in which BMI, WHR and physical activity were each independently associated with hyperinsulinaemia. In addition, we found that walking, the most common form of physical activity among older adults [30], is associated with lower fasting insulin levels among individuals reporting no regular strenuous recreational physical activity; an observation which suggests that even this form of light-to-moderate physical activity may impart substantial health benefits among postmenopausal women.

The menopause transition is associated with a number of metabolic changes which adversely impact risk for both cardiovascular disease and Type 2 diabetes, principally the development of an atherogenic lipid profile and alterations in glucose metabolism. In addition, weight gain, android fat patterning and intramuscular fat deposition, along with unfavourable changes in diet and physical inactivity all occur with greater frequency with ageing and may exacerbate the physiological disturbances attributed to loss of ovarian function. Hyperinsulinaemia in post-menopausal women may therefore be the result of complex interactions between peripheral insulin sensitivity, impaired pancreatic function, less effective inhibition of hepatic glucose output, and decreased insulin clearance [16].

Our findings pertaining to ethnic differences in fasting insulin levels are also of interest. It has commonly been assumed that obesity and low rates of physical activity are the underlying factors which account for ethnic disparities in both hyperinsulinaemia and the incidence of Type 2 diabetes. Precise physiological and radiological estimates of adiposity were not available in this study and therefore residual differences in insulin levels because of obesity beyond that accounted for by BMI and WHR may persist. However, despite this limitation, our epidemiological data and those of others raise the possibility that there may be unexplained, metabolic differences between ethnic groups. For instance, several studies have demonstrated that both African-Americans [31] and Hispanics [24] have lower rates of insulin clearance as well as increased 
82 Correlates of hyperinsulinaemia in women - A. D. Pradhan et al.

Table 3 Crude and adjusted odds ratio for elevated fasting insulin* according to risk factors for Type 2 diabetes

\begin{tabular}{|c|c|c|c|c|}
\hline \multirow[b]{2}{*}{ Characteristic } & \multicolumn{2}{|c|}{ Crude (age-adjusted) } & \multicolumn{2}{|c|}{ Multivariable adjusted $\dagger$} \\
\hline & \multicolumn{2}{|c|}{ Odds ratio $95 \% \mathrm{CI}$} & \multicolumn{2}{|c|}{ Odds ratio $95 \%$ CI } \\
\hline \multicolumn{5}{|l|}{ Age (years) } \\
\hline $50-54$ & Ref & - & Ref & - \\
\hline $55-59$ & 1.05 & $0.81-1.36$ & 1.04 & $0.78-1.39$ \\
\hline $60-64$ & 1.11 & $0.86-1.43$ & 1.22 & $0.92-1.62$ \\
\hline $65-69$ & 0.96 & $0.74-1.24$ & 1.07 & $0.80-1.44$ \\
\hline $70-74$ & 1.08 & $0.81-1.44$ & 1.31 & $0.95-1.81$ \\
\hline$>75$ & 0.97 & $0.65-1.42$ & 1.43 & $0.93-2.20$ \\
\hline$P$-trend & & 0.93 & & 0.06 \\
\hline \multicolumn{5}{|l|}{ Education } \\
\hline College degree or higher & Ref & - & Ref & - \\
\hline School after high school & 1.34 & $1.12-1.61$ & 1.16 & $0.95-1.42$ \\
\hline High school diploma or GED & 1.42 & $1.14-1.78$ & 1.10 & $0.86-1.41$ \\
\hline Less than high school & 1.62 & $1.20-2.18$ & 1.19 & $0.85-1.67$ \\
\hline$P$-trend & & 0.001 & & 0.28 \\
\hline \multicolumn{5}{|l|}{ Body mass index ( $\mathrm{kg} / \mathrm{m}^{2} ;$ quartiles $)$} \\
\hline$<24.4$ & Ref & - & Ref & - \\
\hline $24.4-27.6$ & 1.86 & $1.39-2.49$ & 1.33 & $0.97-1.82$ \\
\hline $27.7-31.9$ & 3.73 & $2.84-4.90$ & 2.20 & $1.62-2.99$ \\
\hline$>31.9$ & 9.77 & $7.48-12.77$ & 5.00 & $3.67-6.83$ \\
\hline$P$-trend & & $<0.001$ & & $<0.001$ \\
\hline \multicolumn{5}{|l|}{ Waist-hip ratio (quartiles) } \\
\hline$<0.76$ & Ref & - & Ref & - \\
\hline $0.76-0.80$ & 1.85 & $1.40-2.43$ & 1.70 & $1.27-2.28$ \\
\hline $0.81-0.86$ & 3.42 & $2.63-4.44$ & 2.58 & $1.95-3.40$ \\
\hline$>0.86$ & 6.24 & $4.83-8.05$ & 4.06 & $3.09-5.35$ \\
\hline$P$-trend & & $<0.001$ & & $<0.001$ \\
\hline \multicolumn{5}{|l|}{ Adult weight change } \\
\hline Maintained weight within $10 \mathrm{lb}$ & Ref & - & Ref & - \\
\hline Maintained weight loss & 0.95 & $0.48-1.88$ & 1.23 & $0.60-2.54$ \\
\hline Weight fluctuation $>10 \mathrm{lb}$ & 2.46 & $1.97-3.06$ & 1.29 & $1.00-1.65$ \\
\hline Steady gain in weight & 3.07 & $2.47-3.80$ & 1.62 & $1.27-2.07$ \\
\hline$P$-trend & & $<0.001$ & & 0.001 \\
\hline \multicolumn{5}{|l|}{ Family history of diabetes } \\
\hline No & Ref & - & Ref & - \\
\hline Yes & 1.27 & $1.09-1.49$ & 1.09 & $0.91-1.29$ \\
\hline$P$-value & & 0.002 & & 0.35 \\
\hline \multicolumn{5}{|l|}{ Smoking status } \\
\hline Never smoked & Ref & - & Ref & - \\
\hline Past smoker & 0.90 & $0.76-1.06$ & 0.81 & $0.67-0.98$ \\
\hline Current smoker & 0.55 & $0.39-0.77$ & 0.48 & $0.33-0.71$ \\
\hline$P$-value & & 0.001 & & $<0.001$ \\
\hline \multicolumn{5}{|l|}{ Alcohol intake } \\
\hline Non-drinker & Ref & - & Ref & - \\
\hline Past drinker & 1.37 & $1.05-1.79$ & 1.35 & $1.00-1.82$ \\
\hline$<1$ drink per month & 1.26 & $0.94-1.68$ & 1.18 & $0.86-1.63$ \\
\hline$<1$ drink per week & 1.09 & $0.84-1.42$ & 1.36 & $1.01-1.83$ \\
\hline 1-6 drinks per week & 0.77 & $0.58-1.01$ & 1.09 & $0.80-1.49$ \\
\hline$>7$ drinks per week & 0.66 & $0.46-0.95$ & 1.00 & $0.66-1.51$ \\
\hline$P$-trend & & $<0.001$ & & 0.72 \\
\hline \multicolumn{5}{|l|}{ MHT usage status } \\
\hline Never used & Ref & - & Ref & - \\
\hline Past user & 1.09 & $0.89-1.33$ & 1.19 & $0.77-1.16$ \\
\hline Current user & 0.69 & $0.57-0.83$ & 0.94 & $0.96-1.49$ \\
\hline$P$-value & & $<0.001$ & & 0.17 \\
\hline \multicolumn{5}{|c|}{ Energy expended from all recreational physical activity (kcal/kg/week) } \\
\hline 0 & Ref & - & Ref & - \\
\hline $0.10-3.75$ & 0.69 & $0.55-0.87$ & 0.78 & $0.60-1.00$ \\
\hline $3.76-9.25$ & 0.61 & $0.48-0.77$ & 0.80 & $0.62-1.03$ \\
\hline $9.26-17.5$ & 0.46 & $0.36-0.58$ & 0.69 & $0.53-0.90$ \\
\hline
\end{tabular}


Table 3 Continued

\begin{tabular}{|c|c|c|c|c|}
\hline \multirow{3}{*}{$\begin{array}{l}\text { Characteristic } \\
>17.5\end{array}$} & \multicolumn{2}{|c|}{ Crude (age-adjusted) } & \multicolumn{2}{|c|}{ Multivariable adjusted $\dagger$} \\
\hline & \multicolumn{2}{|c|}{ Odds ratio $95 \% \mathrm{CI}$} & \multicolumn{2}{|c|}{ Odds ratio $95 \% \mathrm{CI}$} \\
\hline & 0.32 & $0.24-0.41$ & 0.53 & $0.40-0.71$ \\
\hline$P$-trend & & $<0.001$ & & $<0.001$ \\
\hline \multicolumn{5}{|c|}{ Minutes per week of moderate or strenuous recreational physical activity } \\
\hline 0 & Ref & - & Ref & - \\
\hline $1-45$ & 0.91 & $0.73-1.14$ & 0.97 & $0.76-1.24$ \\
\hline $46-100$ & 0.60 & $0.47-0.76$ & 0.74 & $0.57-0.96$ \\
\hline $101-210$ & 0.49 & $0.38-0.63$ & 0.72 & $0.54-0.94$ \\
\hline$>210$ & 0.37 & $0.27-0.49$ & 0.60 & $0.43-0.82$ \\
\hline$P$-trend & & $<0.001$ & & $<0.001$ \\
\hline \multicolumn{5}{|c|}{ Energy expended from walking $(\mathrm{kcal} / \mathrm{kg} /$ week $) \mathbb{S}$} \\
\hline 0 & Ref & - & Ref & - \\
\hline $0.10-2.50$ & 0.79 & $0.63-0.99$ & 0.80 & $0.62-1.03$ \\
\hline $2.51-5.00$ & 0.50 & $0.38-0.66$ & 0.64 & $0.47-0.86$ \\
\hline $5.01-8.75$ & 0.54 & $0.40-0.73$ & 0.67 & $0.48-0.92$ \\
\hline$>8.75$ & 0.49 & $0.36-0.66$ & 0.73 & $0.52-1.01$ \\
\hline$P$-trend & & $<0.001$ & & 0.02 \\
\hline
\end{tabular}

GED, General Equivalency Diploma; Ref, reference group.

*According to the following ethnicity-specific 75th percentile cut points (pmol/1): non-Hispanic White people 85.4; African-Americans 108.7; Hispanics 108.3; American Indian/Alaskan Native 95.1; Asian/Pacific Islander 84.0; Unknown 77.1.

†Adjusted for age (5-year categories), education (college degree or greater, school after high school, high school, diploma or GED, less than high school), BMI (linear continuous), WHR (linear continuous), weight change (maintained weight within $10 \mathrm{lb}$, lost weight and maintained, steady gain or weight fluctuation greater than $10 \mathrm{lb}$ ), family history of DM (no/yes), smoking (never, past or current), alcohol consumption (non-drinker, past drinker, $<1 \mathrm{drink} / \mathrm{month},<1 \mathrm{drink} /$ week, 1-6 drinks/week or 7+ drinks/week), total energy expenditure (linear continuous), and MHT use never/past/ current).

$\ddagger$ This model does not include total energy expended from recreational physical activity.

\$This model does not include total energy expended from recreational physical activity and is limited to those reporting no other strenuous recreational physical activity $(n=2718)$.

insulin secretion $[23,24]$ as compared with non-Hispanic White people. Studies among African-American women also implicate differences in resting energy expenditure [24], variable metabolic effects of leptin [32], and increased intramuscular fat deposition [33]. The latter finding is of particular interest, as this body composition characteristic is associated with insulin resistance [34] and participation in a weight loss and structured walking programme (30-45 min on three occasions per week) may lead to beneficial changes in lean tissue fat content among older obese women [35].

Our observations pertaining to BMI and WHR are consistent with prior studies of younger individuals and studies which included smaller numbers of post-menopausal women. In the current analysis, obesity appeared to be the most important independent predictor in all multivariable models. In addition, our findings that adult weight gain is associated with a $30-$ $60 \%$ increase in odds for elevated fasting insulin is congruent with results from the Nurses' Health Study [36] in which even modest weight gain $(5-6.9 \mathrm{~kg})$ after age 18 years among non-obese women $\left(<22 \mathrm{~kg} / \mathrm{m}^{2}\right)$ was associated with a 2 -fold increase in risk of Type 2 diabetes, as compared with women who maintained a stable weight.

Our finding that past and current smokers had lower odds of hyperinsulinaemia in comparison with non-smokers should be interpreted with caution as several, but not all, prospective evaluations have shown a positive and graded association between smoking and the incidence of Type 2 diabetes. While several studies have found strong relationships between smoking and markers of insulin resistance, others have demonstrated lower levels of fasting insulin [37] and suggested a negative effect on pancreatic $\beta$-cell function. It is also possible that the current findings may partly reflect residual confounding by obesity as smokers tended to be leaner (BMI among current vs. never smokers: 27.8 vs. $28.6 \mathrm{~kg} / \mathrm{m}^{2}, P=0.03$ ). Prospective studies utilizing both baseline and follow-up assessment of smoking status, change in weight and fasting insulin may offer additional insight in this regard.

Our data pertaining to physical activity are concordant with a report from the Insulin Resistance Atherosclerosis Study [38], in which both vigorous and non-vigorous physical activity were independently associated with improved insulin sensitivity as measured by intravenous glucose tolerance testing among a multi-ethnic population of middle-aged men and women. Similar associations were noted in the smaller CrossCultural Activity Participation Study [39] in which moderateintensity physical activity was related to declines in fasting insulin among African-American, Native American and Caucasian women. Our findings also concur with those from the Nurses' Health Study [40] in which energy expended from walking was independently associated with a graded decline 
in diabetes risk among women aged 30-55 years at baseline. Overall, our observations extend these earlier reports by suggesting that similar benefits might be achieved with regular physical activity among post-menopausal women.

Several important limitations of our analysis merit discussion. First, we interpreted elevated fasting insulin as an indirect measure of insulin resistance and risk for Type 2 diabetes. However, fasting insulin levels are determined not only by the degree of insulin sensitivity but also by $\beta$-cell secretory function and insulin clearance. Among non-diabetic subjects, this surrogate index of insulin resistance is moderately well correlated with more direct glucose clamp [41] and minimal model [42] techniques, and is highly correlated with the homeostasis model (HOMA IR, $r=0.98$ ) [43]. In addition, our insulin assay had $40 \%$ cross-reactivity with pro-insulin which was not directly measured in this study. As ethnic differences in proinsulin may occur, we cannot precisely determine to what extent elevations in this insulin precursor may have affected our results. However, the overall ratio of fasting pro-insulin to specific insulin in two prior studies of non-diabetic predominantly White [44] and Mexican-American [45] populations has been demonstrated to be low. Second, our use of BMI and WHR as indices of total and central obesity may have introduced non-differential misclassification. BMI may be an imprecise marker of overall adiposity because of unaccounted differences in lean tissue mass and body fat distribution. Also, our use of the WHR as an indicator of abdominal adiposity does not distinguish visceral from subcutaneous adipose depots. However, these indices are practical, non-invasive measures which are more likely to be used as clinical tools for usual risk assessment. Third, as our data are cross-sectional in nature, inferences regarding causality and clinical relevance are hypothesis generating. However, to our knowledge, these data represent one of the largest studies to evaluate potential correlates of hyperinsulinaemia among an ethnically diverse population of post-menopausal women.

In conclusion, in this large ethnically diverse nationwide study of post-menopausal women, we have found ethnicity to be strongly and independently associated with fasting insulin levels and have also identified several modifiable correlates of fasting hyperinsulinaemia. These findings may be helpful in the design of strategies for prevention of both Type 2 diabetes and coronary heart disease among this growing segment of the US population.

\section{Competing interests}

None declared.

\section{Acknowledgements}

The research upon which this publication is based was performed pursuant to Contract No. N01-WH-3-2109 with the National Institutes of Health, Department of Health and Human Services.

\section{References}

1 Lundgren H, Bengtsson C, Blohme G, Lapidus L, Waldenstrom J. Fasting serum insulin concentration and early insulin response as risk determinants for developing diabetes. Diabet Med 1990; 7: 407413.

2 Charles MA, Fontbonne A, Thibult N, Warnet JM, Rosselin GE, Eschwege E. Risk factors for NIDDM in white population. Paris Prospective Study. Diabetes 1991; 40: 796-799.

3 Skarfors ET, Selinus KI, Lithell HO. Risk factors for developing noninsulin dependent diabetes: a 10-year follow-up of men in Uppsala. Br Med J 1991; 303: 755-760.

4 Saad MF, Knowler WC, Pettitt DJ, Nelson RG, Mott DM, Bennett $\mathrm{PH}$. The natural history of impaired glucose tolerance in the Pima Indians. N Engl J Med 1988; 319: 1500-1506.

5 Haffner SM, Stern MP, Mitchell BD, Hazuda HP, Patterson JK. Incidence of type II diabetes in Mexican Americans predicted by fasting insulin and glucose levels, obesity, and body-fat distribution. Diabetes 1990; 39: 283-288.

6 Mykkanen L, Kuusisto J, Pyorala K, Laakso M. Cardiovascular disease risk factors as predictors of type 2 (non-insulin-dependent) diabetes mellitus in elderly subjects. Diabetologia 1993; 36: 553-559.

7 Lillioja S, Mott DM, Spraul M, Ferraro R, Foley JE, Ravussin E et al. Insulin resistance and insulin secretory dysfunction as precursors of non-insulin-dependent diabetes mellitus. Prospective studies of Pima Indians. N Engl J Med 1993; 329: 1988-1992.

8 Fontbonne A, Charles MA, Thibult N, Richard JL, Claude JR, Warnet JM et al. Hyperinsulinaemia as a predictor of coronary heart disease mortality in a healthy population: the Paris Prospective Study, 15-year follow-up. Diabetologia 1991; 34: 356-361.

9 Pyorala M, Miettinen H, Laakso M, Pyorala K. Hyperinsulinemia predicts coronary heart disease risk in healthy middle-aged men: the 22-year follow-up results of the Helsinki Policemen Study. Circulation 1998; 98: 398-404.

10 Ruige JB, Assendelft WJ, Dekker JM, Kostense PJ, Heine RJ, Bouter LM. Insulin and risk of cardiovascular disease: a meta-analysis. Circulation 1998; 97: 996-1001.

11 Harris MI. Non-insulin-dependent diabetes mellitus in black and white Americans. Diabetes Metab Rev 1990; 6: 71-90.

12 Cowie CC, Harris MI, Silverman RE, Johnson EW, Rust KF. Effect of multiple risk factors on differences between blacks and whites in the prevalence of non-insulin-dependent diabetes mellitus in the United States. Am J Epidemiol 1993; 137: 719-732.

13 Stern MP, Rosenthal M, Haffner SM, Hazuda HP, Franco LJ. Sex difference in the effects of sociocultural status on diabetes and cardiovascular risk factors in Mexican Americans. The San Antonio Heart Study. Am J Epidemiol 1984; 120: 834-851.

14 Hamman RF, Marshall JA, Baxter J, Kahn LB, Mayer EJ, Orleans M et al. Methods and prevalence of non-insulin-dependent diabetes mellitus in a biethnic Colorado population. The San Luis Valley Diabetes Study. Am J Epidemiol 1989; 129: 295-311.

15 Harris MI, Flegal KM, Cowie CC, Eberhardt MS, Goldstein DE, Little RR et al. Prevalence of diabetes, impaired fasting glucose, and impaired glucose tolerance in US adults. The Third National Health and Nutrition Examination Survey, 1988-94. Diabetes Care 1998; 21: $518-524$.

16 Gaspard UJ, Gottal JM, van den Brule FA. Post-menopausal changes of lipid and glucose metabolism: a review of their main aspects. Maturitas 1995; 21: 171-178.

17 Donahue RP, Orchard TJ, Becker DJ, Kuller LH, Drash AL. Sex differences in the coronary heart disease risk profile: a possible role for insulin. The Beaver County Study. Am J Epidemiol 1987; 125: 650-657.

18 Donahue RP, Bean JA, Donahue RA, Goldberg RB, Prineas RJ. Insulin response in a triethnic population: effects of sex, ethnic origin, and body fat. Miami Community Health Study. Diabetes Care 1997; 20 : $1670-1676$. 
19 The Women's Health Initiative Study Group. Design of the Women's Health Initiative clinical trial and observational study. Control Clin Trials 1998; 19: 61-109.

20 Ainsworth BE, Haskell WL, Whitt MC, Irwin ML, Swartz AM, Strath SJ et al. Compendium of physical activities: an update of activity codes and MET intensities. Med Sci Sports Exerc 2000; 32: S498504.

21 Patterson RE, Kristal AR, Tinker LF, Carter RA, Bolton MP, AgursCollins T. Measurement characteristics of the Women's Health Initiative food frequency questionnaire. Ann Epidemiol 1999; 9: 178-187.

22 Balkau B, Charles MA. Comment on the provisional report from the WHO consultation. European Group for the Study of Insulin Resistance (EGIR) Diabet Med 1999; 16: 442-443.

23 Boyko EJ, Keane EM, Marshall JA, Hamman RF. Higher insulin and C-peptide concentrations in Hispanic population at high risk for NIDDM. San Luis Valley Diabetes Study. Diabetes 1991; 40: 509-515.

24 Haffner SM, D’Agostino R, Saad MF, Rewers M, Mykkanen L, Selby J et al. Increased insulin resistance and insulin secretion in non-diabetic African-Americans and Hispanics compared with non-Hispanic whites. The Insulin Resistance Atherosclerosis Study. Diabetes 1996; 45: $742-748$.

25 Harris MI, Cowie CC, Gu K, Francis ME, Flegal K, Eberhardt MS. Higher fasting insulin but lower fasting C-peptide levels in African Americans in the US population. Diabetes Metab Res Rev 2002; 18: 149-155.

26 Campbell AJ, Busby WJ, Horwath CC, Robertson MC. Relation of age, exercise, anthropometric measurements, and diet with glucose and insulin levels in a population aged 70 years and over. Am J Epidemiol 1993; 138: 688-696.

27 Stevenson ET, Davy KP, Seals DR. Hemostatic, metabolic, and androgenic risk factors for coronary heart disease in physically active and less active post-menopausal women. Arterioscler Thromb Vasc Biol 1995; 15: 669-677.

28 Barrett-Connor E, Schrott HG, Greendale G, Kritz-Silverstein D, Espeland MA, Stern MP et al. Factors associated with glucose and insulin levels in healthy post-menopausal women. Diabetes Care 1996; 19: 333-340.

29 Brown MD, Korytkowski MT, Zmuda JM, McCole SD, Moore GE, Hagberg JM. Insulin sensitivity in post-menopausal women: independent and combined associations with hormone replacement, cardiovascular fitness, and body composition. Diabetes Care 2000; 23 : 1731-1736.

30 Siegel PZ, Brackbill RM, Heath GW. The epidemiology of walking for exercise: implications for promoting activity among sedentary groups. Am J Public Health 1995; 85: 706-710.

31 Osei K, Schuster DP. Ethnic differences in secretion, sensitivity, and hepatic extraction of insulin in black and white Americans. Diabet Med 1994; 11: 755-762.
32 Nicklas BJ, Toth MJ, Goldberg AP, Poehlman ET. Racial differences in plasma leptin concentrations in obese post-menopausal women. J Clin Endocrinol Metab 1997; 82: 315-317.

33 Ryan AS, Nicklas BJ, Berman DM. Racial differences in insulin resistance and mid-thigh fat deposition in post-menopausal women. Obes Res 2002; 10: 336-344.

34 Goodpaster BH, Thaete FL, Simoneau JA, Kelley DE. Subcutaneous abdominal fat and thigh muscle composition predict insulin sensitivity independently of visceral fat. Diabetes 1997; 46: 1579 _ 1585.

35 Ryan AS, Nicklas BJ, Berman DM, Dennis KE. Dietary restriction and walking reduce fat deposition in the midthigh in obese older women. Am J Clin Nutr 2000; 72: 708-713.

36 Colditz GA, Willett WC, Rotnitzky A, Manson JE. Weight gain as a risk factor for clinical diabetes mellitus in women. Ann Intern Med 1995; 122: 481-486.

37 Ostgren CJ, Lindblad U, Ranstam J, Melander A, Rastam L. Associations between smoking and $\beta$-cell function in a non-hypertensive and non-diabetic population. Skaraborg Hypertension Diabetes Project. Diabet Med 2000; 17: 445-450.

38 Mayer-Davis EJ, D’Agostino R Jr, Karter AJ, Haffner SM, Rewers MJ, Saad M et al. Intensity and amount of physical activity in relation to insulin sensitivity: the Insulin Resistance Atherosclerosis Study. J Am Med Assoc 1998; 279: 669-674.

39 Irwin ML, Mayer-Davis EJ, Addy CL, Pate RR, Durstine JL, Stolarczyk LM et al. Moderate-intensity physical activity and fasting insulin levels in women: the Cross-Cultural Activity Participation Study. Diabetes Care 2000; 23: 449-454.

$40 \mathrm{Hu}$ FB, Sigal RJ, Rich-Edwards JW, Colditz GA, Solomon CG, Willett WC et al. Walking compared with vigorous physical activity and risk of type 2 diabetes in women: a prospective study. J Am Med Assoc 1999; 282: 1433-1439.

41 Laakso M. How good a marker is insulin level for insulin resistance? Am J Epidemiol 1993; 137: 959-965.

42 Howard G, Bergman R, Wagenknecht LE, Haffner SM, Savage PJ, Saad MF et al. Ability of alternative indices of insulin sensitivity to predict cardiovascular risk: comparison with the 'minimal model'. Insulin Resistance Atherosclerosis Study (IRAS) Investigators. Ann Epidemiol 1998; 8: 358-369.

43 Haffner SM, Miettinen H, Stern MP. The homeostasis model in the San Antonio Heart Study. Diabetes Care 1997; 20: 1087-1092.

44 Pradhan AD, Manson JE, Meigs JB, Rifai N, Buring JE, Liu S et al. Insulin, proinsulin, proinsulin: insulin ratio, and the risk of developing type 2 diabetes mellitus in women. Am J Med 2003; 114: 438 444.

45 Haffner SM, Bowsher RR, Mykkanen L, Hazuda HP, Mitchell BD, Valdez RA et al. Proinsulin and specific insulin concentration in highand low-risk populations for NIDDM. Diabetes 1994; 43: 14901493. 